\title{
Production of septal fibrosis of the liver by means of foreign protein injections into rats
}

\author{
Produção de fibrose septal do fígado por injeções de proteínas estranhas \\ Bruna Magalhães Gotardo', Rodrigo Guimarães Andrade', Ludmila Fernandes Oliveira1 \\ and Zilton A. Andrade ${ }^{2}$
}

\begin{abstract}
Similarities and differences in antigenic humoral responses and electrophoretic patterns between Capillaria hepatica and pig-serum were investigated as a contribution to the understanding of hepatic fibrosis induced by the parenteral administration of foreign proteins. Only two out of 10 rats receiving repeated intraperitoneal injections of an extract of Capillaria hepatica-infected mouse liver presented septal hepatic fibrosis (20\%). Under the same experimental conditions, 4 out of 9 rats (44.4\%) developed septal fibrosis following whole pig-serum administration. Injections of normal mouse liver extracts did not result in hepatic fibrosis. Since a $100 \%$ septal fibrosis rate is observed in experimentally Capillaria hepatica-infected rats, it appeared that Capillaria hepatica products continuously released from inside the liver creates a much more effective fibrosis inducing mechanism than the parenteral administration of such factors. Thus, repeated peritoneal administration of a foreign protein to rats would not reveal the full fibrogenic potential it may have under natural conditions.
\end{abstract}

Key-words: Capillaria hepatica. Hepatic fibrosis. Pig-serum model.

Resumo Para se investigar o potencial fibrogênico de materiais derivados da Capillaria hepatica foi feita uma tentativa para se induzir fibrose hepática septal em ratos, através de injeções intraperitoneais repetidas de um extrato de fígado de camundongo infectado pela Capillaria hepática. Dois dos 10 ratos assim tratados desenvolveram fibrose. Comparativamente, 4 dos 9 ratos que receberam injeções de soro de porco desenvolveram fibrose septal do fígado, enquanto nenhuma fibrose apareceu em 10 ratos tratados com extratos de fígado normal de camundongo. Uma vez que, na infecção natural de ratos pela Capillaria hepatica, a fibrose aparece em $100 \%$ dos casos, fica evidente que a administração intraperitoneal de uma substância não revela inteiramente o seu potencial fibrogênico.

Palavras-chaves: Capillaria hepatica. Fibrose septal hepática. Modelo do soro de porco.

Considering that a prominent role has been attributed to immunological factors in the pathogenesis of hepatic fibrosis, several attempts have been made to produce hepatic fibrosis by immunological means. This has been attempted through repeated injections of foreign proteins into several experimental animal species $^{5} 711$. The most reproducible and consistent model was obtained with injections of pig-serum into rats ${ }^{13}$. After daily intraperitoneal injections of $1 \mathrm{ml}$ whole pig-serum or its albumin fraction into rats, a fine and diffuse septal fibrosis develops along the acinar zone III of the liver by the $16^{\text {th }}$ week on. The fibrous septa connect portal spaces to portal spaces and to central veins, isolating portions of the liver parenchyma, resulting in a final morphologic picture of cirrhosis ${ }^{14}$, although in the absence of signs of portal hypertension and hepatocellular failure ${ }^{16}$.

The pig-serum model has been used for testing antifibrosis drugs $^{9}$, for investigation into hepatic fibrosis pathogenesis ${ }^{141314}$ and hepatic physiopathology ${ }^{16}$. The immunological basis of the model has been determined by the demonstration that rats made tolerant to pigserum do not produce fibrosis or serum antibodies when repeatedly injected with such serum ${ }^{4}$.

Following the same protocol as that originally described by Paronetto \& Popper $^{13}$, the rates of fibrosis obtained by different authors have somewhat varied, between $40 \%$ and $75 \%$. This is not surprising,

\footnotetext{
1. Medical students (PIBIC fellowships). 2. Laboratory of Experimental Pathology, Centro de Pesquisas Gonçalo Moniz da Fundação Oswaldo Cruz, Salvador, BA, Brasil.

Supported by PAPES III (FIOCRUZ)

Address to: Dr. Zilton A. Andrade. Department of Experimental Pathology, Centro de Pesquisa Gonçalo Moniz, FIOCRUZ, Rua Valdemar Falcão, 121, 41295-001 Salvador, BA, Brasil.

Recebido para publicação em 11/6/2003

Aceito em 1/9/2003
} 
considering the complex role that host factors may play during immunopathological responses in general. However, with a similar model of septal fibrosis, described by Ferreira \& Andrade ${ }^{8}$ in rats infected with the helminth Capillaria hepatica, a $100 \%$ fibrosis-rate was observed, regardless of parasite load ${ }^{12}$.

The differences in the rate of fibrosis formation between the two models stimulated a trial to induce hepatic fibrosis by repeated intraperitoneal injections of an extract rich in $C$. hepatica materials into rats. The present investigation aimed to observe the similarities and differences between the fibrogenic potential of pig serum and $C$. hepatica when the method of intraperitoneal injections is used. Such a trial appeared interesting as a means to observe to what extent it could reveal the fibrogenic potential of a substance.

\section{MATERIAL AND METHODS}

Thirty 8-week old Wistar rats of both sexes, weighing approximately $200 \mathrm{~g}$, and maintained on a commercial balanced diet and water ad libitum, were used. They were divided into 3 groups of ten animals each.

Group 1 received intraperitoneal injections of $1 \mathrm{ml}$ of a saline liver extract. A total of 26 injections (2 per week, during 13 weeks) was performed. The extract was made from the livers of mice heavily infected with C. hepatica. Young adult mice were inoculated with 300 embryonated $C$. hepatica eggs by means of a gastric tube. The technique for the preparation of the $C$. hepatica inoculum to infect mice has been described elsewhere ${ }^{10}$. Forty days after inoculation the animals were sacrificed. Their livers containing numerous eggs and dead and live adult worms were removed, cleared from debris and excess blood, and homogenized in a blender $(1,000$ $\mathrm{rpm} / 3 \mathrm{~min}$ ) in the presence of a small amount of saline solution. The material was submitted to a series of freezing and thawing procedures. After centrifugation at 3,000 rpm during $5 \mathrm{~min}$, the supernatant was collected and stored at $-80^{\circ} \mathrm{C}$, distributed into several aliquots. The protein concentration of this extract was $4,811 \mathrm{mg} / \mathrm{ml}$, measured by the BCA Protein Assay Reagent Kit (Pierce, Rockford, II, USA).

Group 2 was similar to group 1, except that the $C$. hepatica liver extract was replaced by pig serum. The serum was collected from the peripheral blood of healthy adult pigs. Its protein concentration was $6,210 \mathrm{mg} / \mathrm{ml}$.

Group 3 was also similar to the above two groups, but the animals received intraperitoneal injections of a normal mouse liver extract. The preparation of the extract from normal mouse liver followed all the steps used for the infected livers. Its protein concentration reached $2,768 \mathrm{mg} / \mathrm{ml}$.

Three days after the animals had received their 26th intraperitoneal injection, they were submitted to a liver biopsy. Fragments of the liver were fixed in $10 \%$ neutral formalin for 48 hours, followed by paraffin embedding and sectioning in a microtome. The $5 \mathrm{~mm}$ thick sections were stained with hematoxylin and eosin, and the Sirius-red method for collagen. Occasionally, the PAS-method, with or without previous diastase treatment of the sections, was used.

Sera were collected from all animals at the time of sacrifice for the detection of serum antibodies against C. hepatica, pig serum and normal mouse liver, by an ELISA method.

The liver extracts used, and the pig serum were also analyzed for the molecular composition of proteins by means of SDS-polyacrylamide gel electrophoresis with a reducer agent (2-mercaptoethanol) in a MiniProtean 3 Electrophoresis Cell (BIO-RAD) using 10\% acrylamide.

Sera were submitted to ELISA test for detection of total Ig antibodies, by using a goat anti-rat IgG conjugated to peroxidase (Sigma). The plates were sensitized with $10 \mathrm{mg} / \mathrm{ml} /$ per well of $C$. hepatica-egg antigen, diluted in carbonate buffer, $\mathrm{pH}$ 9.9. Reading was done on a microplate reader Molecular devices-Thermomax (Sunnyvalle, CA, USA) spectrophotometer, under wavelength $450 \mathrm{~mm}$, connected to a computer running MDSSoft Max.

\section{RESULTS}

Repeated intraperitoneal injections with either of the two extracts or with pig-serum were well tolerated by the experimental animals. At the moment the surgical biopsy was performed, the capsule of the liver appeared dark red, smooth, shiny and transparent in all cases. No gross abnormalities in conformation or size of the liver were noted. Microscopically, the presence of thin and long fibrous septa, crisscrossing the hepatic parenchyma along the acinar zone III, was evident in 4 out of 9 rats treated with pig-serum and in 2 out of 10 of those treated with $C$. hepatica extracts (Figure 1). No septal fibrosis developed in the livers of rats treated with normal mouse liver extracts. The only other microscopic finding observed, consisted of a mild to moderate infiltration by a mixture of polymorphonuclear and mononuclear leukocytes, limited to the portal spaces and observed in all the animals, including those injected with normal liver extracts. This histological picture was taken as representative of non-specific reactive hepatitis. In rats receiving injections of $C$. hepatica extracts, a brown, homogeneous, PAS positive-diastase resistant pigment was occasionally present within macrophages. This was probably derived from a wax-like material present in the worm tegument and the parasite egg shell, which is strongly PAS-positive and diastase-resistant. 

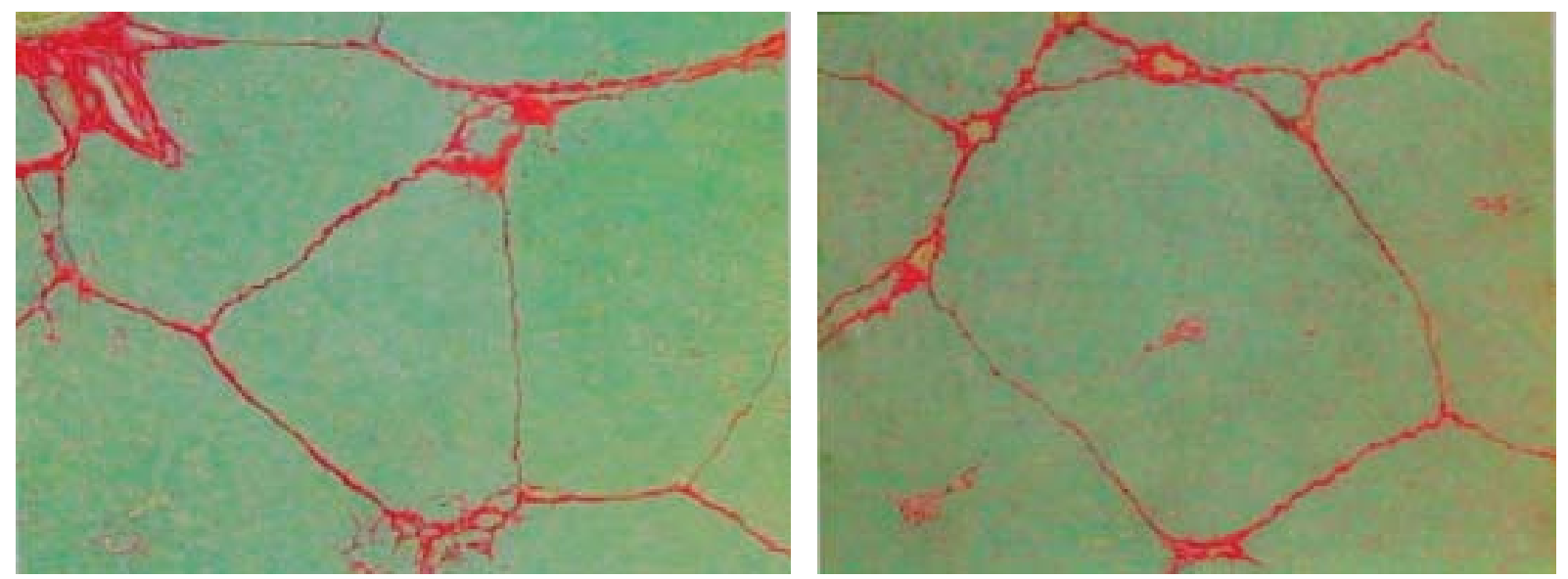

Figure 1 - Septal fibrosis of the liver observed in a rat repeatedly injected with an extract from a Capillaria hepatica-infected mouse liver. Thin and long fibrous septa, running along the acinar zone III, connecting portal spaces to portal spaces and sometimes forming a polygonal figure, leaving a central vein at its center. Picro-sirius-red method for collagen. $200 X$.

Animals injected with normal liver extracts or C. hepatica extracts developed serum antibodies only against their respective extracts. Results for antiC. hepatica and anti-pig-serum antibodies detected by ELISA in the sera of rats are depicted in Figure 2.

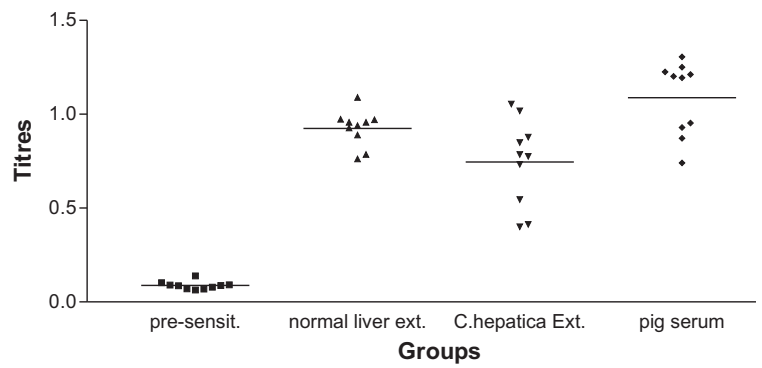

Figure 2 - Serum antibody titers presented by rats against different antigens: extracts from normal mouse liver extract; extract of Capillaria hepatica-infected liver; and pig-serum.

Eletrophoresis of $C$. hepatica extracts revealed several bands which were not present in the extracts from normal liver (Figure 3 - arrows). These are probably $C$. hepatica-derived, one heavy-chain, with correspondence to pig-serum, but not found in normal liver extract. There were also several light-chain bands, two of them exclusive to $C$. hepatica liver extract. Normal liver extracts presented only two bands in that same region. Otherwise, the remaining bands from normal liver, and liver infected with $C$. hepatica were similar. The band representative of the albumin fraction in pig-serum (60), which is responsible for septal fibrosis production ${ }^{4}$, was also present in both normal and $C$. hepatica-infected livers.

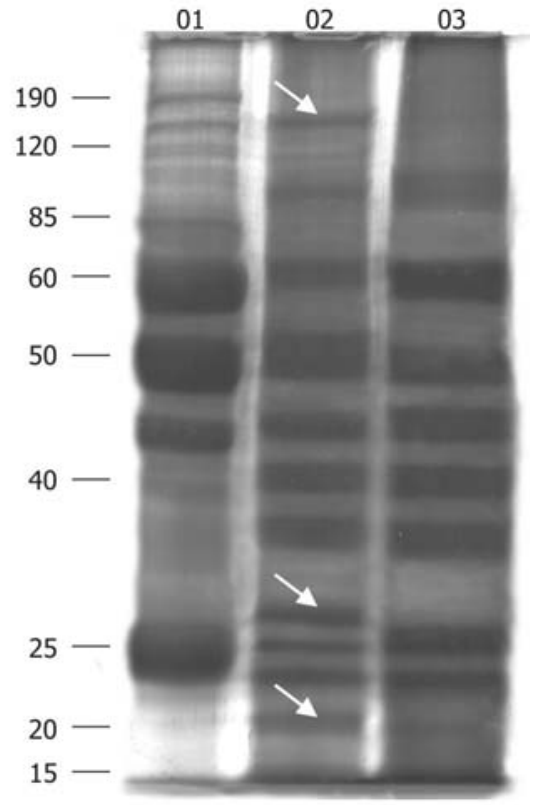

Figure 3 - Electrophoresis showing the band patterns obtained with: pig serum (01); extract from Capillaria hepatica-
infected mouse liver (02); and normal mouse liver extract (03).

\section{DISCUSSION}

The decision to use materials from liver extracts instead of the isolate parasite and its eggs during the present experiments was based on recent findings from our Laboratory, which indicated that neither eggs alone nor the parasite without eggs can induce significant 
septal fibrosis in rats ${ }^{16}$. By injecting purified immature eggs directly into the liver, or by killing the worms before oviposition by means of chemotherapy, Santos et a/15 demonstrated that the presence of lesions containing both disintegrating worms and eggs appeared essential for the full development of disseminated or systematized $C$. hepatica-induced septal fibrosis of the liver in rats. Therefore, not only the parasitic elements, but the products originated from host-parasite interactions, appeared to play a decisive role in the pathogenesis of septal fibrosis of the liver associated with $C$. hepatica infection of rats. Previous experience also indicated that the $C$. hepatica-infected mouse liver was a good source for parasite material. The animal tolerates well a heavy parasite inoculum, exhibiting the liver literally full of worms and eggs by the first month after inoculation with 300 embryonated eggs ${ }^{10}$.

The apparent cross reactivity between pig-serum and C. hepatica deserves further investigation, since both are related to septal fibrosis induction in rats. Unpublished results from this laboratory showed that pig-serum elicited anti-Capillaria antibodies. Electrophoresis data also suggested the presence of common bands at the region of the pig-serum albumin, besides serum independent bands. Albumin is the pig-serum fraction responsible for the induction of septal fibrosis in rats ${ }^{43}$.
Considering all the attempts made to induce hepatic fibrosis by the injections of foreign proteins, that consisting of repeated intraperitoneal injections of pigserum into rats now stands as the most effective. Although $C$. hepatica causes $100 \%$ septal hepatic fibrosis during natural infection in rats, its extracts were not even half as effective, when intraperitoneally injected. The route of administration has already been indicated as a crucial factor in the pathogenesis of hepatic fibrosis induced by repeated injections of foreign proteins. Andrade \& Godoy ${ }^{2}$ demonstrated that rats treated with whole pig serum by subcutaneous injections into the dorsal fat pad failed to develop hepatic fibrosis. Under the same experimental protocol, septal fibrosis developed in $65 \%$ of the animals when the serum was injected instead into the peritoneal cavity. One can imagine that, if the fibrosis stimulating factors are being liberated within the liver, continuously and slowly, their effectiveness is certainly augmented. This detail should be considered to account for the differences between fibrosis production by injections of liver-worm extracts, as compared to actual infection. Coincidentally septal hepatic fibrosis has been described as an important finding in two other parasitic diseases, schistosomiasis $^{3}$ and fascioliasis ${ }^{6}$, in which the disintegrating parasites and their eggs remain within the liver for relatively prolonged periods of time.

\section{REFERENCES}

1. Andrade ZA. Contribution to the study of septal fibrosis of the liver. International Journal of Experimental Pathology 72: 553562, 1991.

2. Andrade ZA, Godoy A. Influence of the route of administration of pig serum in the induction of hepatic septal fibrosis in rats. Memórias do Instituto Oswaldo Cruz 91: 769, 1996.

3. Andrade ZA, Peixoto E, Guerret S, Grimaud JA. Hepatic connective tissue changes in hepatosplenic schistosomiasis. Human Pathology 23: 566-573, 1992.

4. Bhunchet E, Eishi Y, Wake K. Contribution of immune response to the hepatic fibrosis induced by porcine serum. Hepatology 23: 811-817, 1996

5. Blackwell JB. Cirrhosis resulting from repeated injections of antigens. Journal of Pathology and Bacteriology 90: 245-258, 1965.

6. Dargie JD, Armour J, Rushton B, Murray M. Immune mechanisms and hepatic fibrosis in fascioliasis. In: EJL Soulsby (ed) Parasitic Zoonoses. Clinical and experimental studies, Academic Press, New York, p. 249-271, 1974.

7. Fennel $\mathrm{RH}$. Chronic liver disease induced in rats by repeated anaphylactic shock. American Journal of Pathology 47: 173182, 1965.

8. Ferreira LA, Andrade ZA. Capillaria hepatica: a cause of septal fibrosis of the liver. Memórias do Instituto Oswaldo Cruz 88: 441-447, 1993.
9. Fujiwara K, Ogata I, Ohta Y, Hayashi S, Mishiro S, Takatsuki K, Sato $\mathrm{Y}$, Yamada S, Hirata K, Oka H, et al .Decreased collagen accumulation by a prolylhydroxylase inhibitor in pig-seruminduced fibrotic rat liver. Hepatology 8: 804-807, 1988.

10. Gotardo BM, Andrade RG, Andrade ZA. Hepatic pathology in Capillaria hepatica infected mice. Revista da Sociedade Brasileira de Medicina Tropical 33: 341-346, 2000.

11. Longcope WT. Cirrhosis of the liver produced by chronic protein intoxication. Transactions of the Association of American Physicians 28: 497-512, 1913.

12. Oliveira RF, Andrade ZA. Worm load and septal fibrosis of the liver in Capillaria hepatica-infected rats. Memórias do Instituto Oswaldo Cruz 96: 1001-1003, 2001.

13. Paronetto $F$, Popper $\mathrm{H}$. Chronic liver injury induced by immunologic reactions. Cirrhosis following immunization with heterologous sera American Journal of Pathology 49: 1087-1101, 1966.

14. Rubin E, Hutterer F, Popper H. Experimental hepatic fibrosis without hepatocellular regeneration. A kinetic study. American Journal of Pathology 52: 111-120, 1968.

15. Santos AB, Tolentino Junior M, Andrade ZA. Pathogenesis of hepatic septal fibrosis associated with Capillaria hepatica infection of rats. Revista da Sociedade Brasileira de Medicina Tropical 34: 503-506, 2001.

16. Shibayama Y, Nakata K. Significance of septal fibrosis for disturbance of hepatic circulation. Liver 12: 22-25, 1992. 